\title{
Identifying Children at Risk of Intellectual Disability in UNICEF's Multiple Indicator Cluster Surveys: Cross-sectional survey
}

Professor Eric Emerson, PhD (corresponding author: +44 (0)1297 680123;

eric.emerson@lancaster.ac.uk $)^{1,2,3}$

Professor Gwynnyth Llewellyn, PhD ${ }^{1,2}$

1 Centre for Disability Research and Policy, Faculty of Health Sciences, University of Sydney, Sydney, NSW 2141, Australia

2 Centre of Research Excellence in Disability and Health, University of Sydney, Sydney, NSW 2141, Australia

3 Centre for Disability Research, Faculty of Health \& Medicine, Lancaster University, Lancaster, LA1 $4 Y W$, UK

\section{Funding}

No funding was received for this research.

\section{Disclosures}

The authors have no conflicts of interest to declare.

\section{Key words}

Disability, Low and middle-income countries, MICS, UNICEF

\section{Acknowledgements}

We would like to thank the UNICEF's global Multiple Indicator Cluster Surveys (MICS) program for allowing us to use the datasets and Claudia Cappa of UNICEF for providing and update on the revisions to the Early Child Development Index. 


\section{Abstract}

Background. Research on intellectual disability has been criticized for primarily addressing the situation of people in high-income countries.

Objective/Hypothesis. To determine whether MICS6 data on 'functional difficulty associated with learning' (FDAL) in low- and middle-income countries could be used as a proxy indicator for intellectual disability

Methods. Secondary analysis of nationally representative data collected in Round 6 of UNICEF's Multiple Indicator Cluster Surveys (MICS) on 244,915 children in 18 middle- and low-income countries.

Results. The prevalence of FDAL in middle- and low-income countries was broadly similar to the estimated prevalence of intellectual disability in high-income countries. The association between risk of FDAL and household wealth was weak, with alternative measures of developmental delay showing significantly stronger associations with household wealth. The risk of making potential false negative errors in identifying FDAL increases as household wealth and level of maternal education decrease. The risk of making potential false positive errors in identifying FDAL is greater among more highly educated respondents, although this association is only statistically significant among older children.

Conclusions. The use of FDAL as a proxy indicator for intellectual disability cannot be recommended given: (1) it would probably underestimate the overall prevalence of intellectual disability in middle and low income countries; and (2) it is likely to be overestimate prevalence among families with higher socio-economic position (SEP) and underestimate prevalence among families with lower SEP. 


\section{Introduction}

The generation of knowledge from research in relation to intellectual disability has been rightly criticized for its bias in primarily addressing the situation of people with intellectual disability living in high-income countries. ${ }^{1}$ At even a very basic level, little is known about the prevalence or predictors of intellectual disability in low- and middle-income countries. For example, a recent WHO commissioned review of the prevalence of intellectual disabilities identified 26 studies that used robust regional, provincial or national sampling frames. ${ }^{2}$ All but one of these (96\%) were undertaken in high income countries. However, the available evidence on between-country variation in exposure to established determinants of intellectual disability (e.g., household poverty, undernutrition) suggests that the incidence of intellectual disability is likely to be much higher in lower income countries. ${ }^{3-6}$ Although methodologically limited, the sparse available evidence on prevalence supports this hypothesis. ${ }^{2,6}$

One approach to addressing this bias is for researchers to make greater use of existing data from large scale heath surveys undertaken in middle- and low-income countries; one example of which is UNICEF's Multiple Indicator Cluster Survey (MICS) program. MICS was established in 1995 to provide support to middle- and low-income countries to generate robust country-specific data on the wellbeing of young children and mothers. ${ }^{7,8}$ MICS data has been used by several research groups who have focused on the loss of developmental potential among young children in general living in low or middle-income countries. ${ }^{3-5,9-13}$ A proportion of this group is likely to have or be at risk of intellectual disability. ${ }^{14}$

More recently, researchers have used data from the Early Child Development Index (ECDI) $)^{15}$ which is included in MICS to identify three and four year old children in middle and low income countries with 'significant cognitive delay' as an indicator for risk of intellectual disability. ${ }^{16}$ This method has been used to estimate the potential impact of a range of preventative interventions on the prevalence of significant cognitive delay, and investigate aspects of the health and healthcare received by these young children. ${ }^{16-18}$

However, in the latest round of MICS surveys (MICS6 which commenced in 2017) new modules were introduced to identify children with disability. Developed by the Washington Group on Disability Statistics (WGDS: http://www.washingtongroup-disability.com/), the modules are based on informant report of child difficulties in a range of domains. Both the 2-4 year old module and the 517 year old module include an identical item that has the potential for identifying children at risk of intellectual disability. Informants are asked 'compared with children of the same age, does (name) have difficulty learning things?'. Response options are: (1) 'no difficulty'; (2) 'some difficulty'; (3) 'a lot of difficulty'; and (4) 'cannot do at all'. The WGDS recommended cut-off for disability is scoring 3 or 4 on this item.

Initial validation of the new WGDS module (undertaken in three low/middle income countries) estimated the prevalence of severe functional difficulty associated with learning ranging from $0.0 \%$ to $0.4 \%$ in $2-4$ year old children and $0.5 \%$ to $1.9 \%$ in 5-17 year old children. ${ }^{19}$ It should be noted that: (1) the ascertained prevalence 'of severe functional difficulty associated with learning' is markedly lower than the ascertained prevalence of intellectual disability among children in high income countries $(1.8 \%, 95 \% \mathrm{Cl} 1.5 \%-2.1 \%)$, and, as noted above, (2) there exist good grounds for assuming that the prevalence of ID/DD should be higher in low and middle income countries. ${ }^{3,4}, 10,16$

Most screening measures for intellectual disability or child development in general (e.g., the ECDI) collect information on the child's attainments of specific developmental targets (e.g., knowing numbers from 1 to 10). ${ }^{20}$ In contrast the WGDS question asks the informant to make a general 
judgement about their child's progress relative to 'children of the same age'. The use of such a strategy in surveys which are designed to generate robust national level data is based on the assumptions that: (1) parental informants have sufficient knowledge of the learning capacity of 'children of the same age' in their homeland; and (2) there will be no systematic biases in errors made by parental informants as a result of such factors as urban/rural location, household wealth/poverty, or informant level of education. However, it is possible that, given the spatial concentration of household poverty in poorer neighborhoods and the impact of family poverty on early child development, the reference point for poorer families with regard to 'children of the same age' may be other deprived children in the neighborhood, rather than children nationally. As a result, they may risk under-identifying their child as having a functional difficulty.

Indeed, previous research from high-income countries has suggested that the association between parental concerns regarding child development and assessed cognitive functioning may vary with family socio-economic status. Specifically, poorer informants appear likely to not report concerns even when the results of direct cognitive testing suggest grounds for concern (potential false negative errors), while more wealthy informants appear likely to report concerns even when the

results of direct cognitive testing suggest no grounds for concern (potential false positive errors). ${ }^{21}$ In combination, these errors suggest that reliance on parental concerns may underestimate the prevalence of developmental delay among children in poorer families, and overestimate the prevalence of developmental delay among children in wealthier families. Reducing the risk of potential under-ascertainment of childhood disability among poorer families was cited by the WGDS team as one of the reasons for the development of the new MICS modules. ${ }^{22}$

The aims of the present paper are to: (1) to report the ascertained prevalence of 'functional difficulty associated with learning' in 2-17 year old children in a range of low and middle income countries; (2) to determine whether the risk of functional difficulty associated with learning is associated with household wealth and male gender (two reasonably well established risk factors for intellectual disability) ${ }^{2}$ and (3) to determine whether discrepancies between the WGDS measure and independent measures of child functioning collected in MICS varied by household wealth, level of maternal education and urban/rural status.

\section{Method}

We undertook secondary analysis of nationally representative data collected in Rounds 6 (data collected 2017-2019) of MICS. ${ }^{7}$ Following approval by UNICEF, MICS data were downloaded from http://mics.unicef.org/. At the end of the download period (1 May, 2020), data from 18 nationally representative surveys were available for 4 upper-middle, 9 lower-middle and 5 low-income countries.

MICS contains several questionnaire modules. Data used in the present paper were extracted from the household module, the module applied to all children under five living in the household and the module applied to a randomly selected child age 5-17 living in the household. ${ }^{8}$ All countries used cluster sampling methods to derive samples representative of the national population of mothers and young children. Specific details of the sampling procedure used in each country are available at http://mics.unicef.org/.

\section{Functional Difficulty Associated with Learning}

As noted above, both the 2-4 year old module and the 5-17 year old module include an identical item for identifying children with functional difficulty associated with learning. Informants (primarily mothers) are asked 'compared with children of the same age, does (name) have difficulty learning 
things?'. Response options were: (1) 'no difficulty'; (2) 'some difficulty'; (3) 'a lot of difficulty'; and (4) 'cannot do at all'. The WGDS recommended cut-off for functional difficulty associated with learning is scoring 3 or 4 on this item. ${ }^{19}$ Functional difficulty associated with learning data for 5-17 year old children were not collected in one lower middle-income country (Lao PDR). Data were missing for $3.6 \%$ of $2-4$ year old children and $<0.1 \%$ of $5-17$ year old children (excluding Lao PDR) .

\section{Alternative Measures of Potential Developmental Delay}

Significant Cognitive Delay (SCD) (Age 3-4)

The child under five module contained the Early Child Development Index (ECDI), a ten item scale based on milestones that children are expected to achieve by ages 3 and $4 .{ }^{15}$ The ECDI contains four domains; literacy-numeracy, physical, social emotional, and learning. ECDI data were collected on children in the age range 36-59 months. We used all five items from the literacy-numeracy and learning domains to identify children with significant cognitive delay. All items are based on key informant (primarily maternal) report with simple binary (yes/no) response options.

- Literacy-numeracy: Can the child: (1) identify/name at least ten letters of the alphabet; (2) read at least four simple, popular words; (3) name and recognize the symbols of all numbers from 1 to 10 ?

- Learning: Can the child: (4) follow simple directions on how to do something correctly; (5) when given something to do, do it independently?

There are no well-established criteria for using ECDI items to identify children with cognitive delay. In MICS country reports UNICEF considers children under five not to be developmentally 'on track' in literacy-numeracy if they cannot undertake two of the three tasks and not to be developmentally 'on track' in learning if they cannot undertake both tasks. McCoy and colleagues used the latter criteria to identify children with 'cognitive delay'. ${ }^{14}$ We adopted the more stringent criteria suggested by Emerson and colleagues and defined significant cognitive delay as the reported inability to perform all five items. ${ }^{16}$ The five items demonstrated an acceptable degree of internal consistency across the whole sample (alpha $=0.63$ ), although there was some marked between country variation (alpha range $0.35-0.77)$. Complete data to determine significant cognitive delay were missing for $0.4 \%$ of three and four-year-old children.

Low Numeracy (Age 7-14)

MICS6 includes a Foundational Learning Module that directly assesses child attainment in relation to numeracy and literacy. ${ }^{23}$ Initial inspection of the data revealed extensive amounts of missing data in the literacy tasks, especially in the 7-9 year age range. As a result, we focused on numeracy.

Children aged 7-14 were tested on tasks of: (1) number recognition (6 items); (2) identifying the larger of two numbers (5 items); (3) addition (5 items); (4) number sequences (5 items). ${ }^{23} \mathrm{We}$ derived a number correct score for each child (potential range 0-21). We identified children as having limited numeracy if they scored in the bottom decile for their age in the country in which they were living. The Foundational Learning Module was not applied in three upper middle-income and one lower middle-income countries (Iraq, Georgia, Lao PDR, Montenegro). Numeracy data was missing for $5.5 \%$ of children in countries which used the Foundational Learning Module.

\section{Country Characteristics}

Given the commonly reported association between child wellbeing and national wealth in low and middle income countries, ${ }^{24}$ we used World Bank 2018 country classification as upper middle income, lower middle income and low income. ${ }^{25}$ These classifications are based on per capita Gross National Income adjusted for purchasing power parity (pcGNI; expressed as current US\$ rates) using the 
World Bank's Atlas Method. We also downloaded 2018 Atlas Method pcGNI from the World Bank website in May 2020. ${ }^{26,27}$

\section{Household Wealth}

Household wealth is likely to also be associated with variations in children's health and wellbeing. MICS data includes a within-country wealth index for each household. To construct the wealth index, principal components analysis is performed by using information on the ownership of consumer goods, dwelling characteristics, water and sanitation, and other characteristics that are related to the household's wealth, to generate weights for each item. Each household is assigned a wealth score based on the assets owned by that household weighted by factor scores. The wealth index is assumed to capture underlying long-term wealth through information on the household assets. ${ }^{28,29}$ These data were collected in all countries. Data were missing for $<0.1 \%$ of children.

\section{Maternal Education}

The highest level of education received by the child's mother was recorded using country-specific categories. We recoded these data into a three-category measure: (1) no education; (2) primary education; (3) receipt of secondary or higher-level education. These data were collected in all countries. Data were missing for $1.3 \%$ of children.

\section{Urban/Rural Location}

Data were released with a within-country defined binary indicator of urban/rural location for each household. These data were collected in all countries, with no missing data.

\section{Approach to Analysis}

In the first stage of analysis we used simple bivariate descriptive statistics to estimate the prevalence of child disability associated with learning impairment (with 95\% confidence intervals) among 2/4 and $5 / 17$ year-old children for each participating country, with pooled estimates for each country economic classification group and overall.

In the second stage of analysis we used non-parametric correlation coefficients to examine the within-country economic classification group association between functional difficulty and our alternative measures of child development with learning and household wealth. In addition, we used Poison regression with robust standard errors to examine the within-country economic classification group association between functional difficulty and our alternative measures of child development with learning and child gender. Given that numeracy data were only collected in one upper middleincome country, for these and subsequent analyses we excluded countries in which numeracy data was not collected and collapsed upper and lower middle-income countries into one class.

In the final stage of analyses, we used Poison regression with robust standard errors to investigate the extent to which potential false positive and false negative errors for the identification of functional difficulty associated with learning varied with maternal education, household wealth and urban rural location. We coded a potential false positive error when the WGDS module identified a child as having functional difficulty associated with learning and the alternative measure of potential developmental delay was negative (no significant cognitive delay, no low numeracy). We coded no false positive error when the WGDS module identified functional difficulty associated with learning and the alternative measure of potential developmental delay was positive (presence of significant cognitive delay/low numeracy). Similarly, we coded a potential false negative error when the WGDS module did not identify a child as having functional difficulty associated with learning and the alternative measure of potential developmental delay was positive (presence of significant cognitive delay/low numeracy). We coded no false negative error when the WGDS module identified a child as 
not having functional difficulty associated with learning and the alternative measure of potential developmental delay was negative (no significant cognitive delay/low numeracy).

Prevalence estimates were undertaken in IBM SPSS v24 using the complex samples facility to take account of the clustering of observations by country and within country sampling clusters. Withincountry analyses used UNICEF's country-specific child-level sample weights to take account of biases in sampling frames and household and individual level non-response. These weights were calibrated to ensure that the weighted and unweighted sample sizes were equivalent. For pooled analyses we recalibrated the country specific weights to take account of between country differences in the child sampling fraction based on UNICEF's 2019 estimates of the population of children under the age of 5 years and aged 5-17 years. Given the small amount of missing data, complete case analysis was undertaken.

\section{Results}

Data was available for 244,915 children in 18 middle- and low-income countries. Of the children, $50.7 \%$ were male, $57.7 \%$ had mothers who had not received secondary level education, $64.3 \%$ lived in rural settings and $27.6 \%$ lived in households in the poorest quintile for their country of residence.

\section{Prevalence of Functional Difficulty Associated with Learning}

The ascertained prevalence of functional difficulty associated with learning by World Bank Economic Classification Group is presented in Table 1. Pooled estimates suggest that the prevalence of functional difficulty associated with learning significantly increases with age in middle-income countries but significantly decreases with age in low-income countries.

[Insert Table 1]

\section{Association of Functional Difficulty Associated with Learning with Household Wealth and Gender}

Information on the association between household wealth and gender and functional difficulty associated with learning and the two alternative measures of child development are presented in Tables 2 and 3.

[Insert Tables 2 and 3]

The association between the prevalence of functional difficulty associated with learning and household wealth score is weak in all countries and for both age groups. Both alternative measures of developmental delay show a significantly stronger association with household wealth than the WGDS items. At age 2-4 years, male gender is weakly associated with the prevalence of severe functional difficulty associated with learning and significant cognitive delay (SCD), but only in lowincome countries. At older ages male gender is more strongly associated with the prevalence of severe functional difficulty associated with learning in middle- and low-income countries. The association between male gender and low numeracy appears to be moderated by country economic classification; in middle-income countries boys are more likely to have low numeracy while in low income countries, girls are more likely to have low numeracy.

\section{Potential False Negative and False Positive Errors}

Estimates of the relative risk of potential false negative and false positive errors between functional difficulty associated with learning and alternative indicators of developmental delay associated with contextual factors by country classification group are presented in Table 4. 
[Insert Table 5]

Overall, and for both country classification groups, the probability of making potential false negative errors is strongly related to within-country variation in household wealth. For example, respondents in the poorest wealth quintile were over twice as likely than respondents in the richest wealth quintile to make potential false negative errors for young children and over six times more likely to make such errors for older children. Among older children, the magnitude of such risks is significantly higher in low (when compared to middle) income countries. Once the effects of wealth are taken into account, the risk of potential false negative errors also increases at lower levels of maternal education.

Overall, the risk of making potential false positive errors is greater among more highly educated respondents, although this association is only statistically significant among older children and is particularly strong in low-income countries.

\section{Discussion}

\section{Main findings of this study}

Our analyses of data collected on nationally representative samples of 244,915 children in 18 middle- and low-income countries indicated that: (1) the prevalence of functional difficulty associated with learning is broadly similar to the estimated prevalence of intellectual disability in high-income countries; (2) the association between the prevalence of functional difficulty associated with learning and household wealth score is weak, with both alternative measures of developmental delay showing significantly stronger associations with household wealth; (3) male gender was associated with increased prevalence of severe functional difficulty associated with learning; (4) the risk of making potential false negative errors increases as household wealth and level of maternal education decrease; (5) the risk of making potential false positive errors is greater among more highly educated respondents, although this association is only statistically significant among older children.

\section{What is already known on this topic}

Initial validation of the new WGDS module estimated the prevalence of severe functional difficulty associated with learning to range $0.0 \%$ to $0.4 \%$ in $2-4$ year old children, and $0.5 \%$ to $1.9 \%$ in $5-17$ year old children. ${ }^{19}$

\section{What this study adds}

This is the first study to present data on the prevalence of severe functional difficulty associated with learning that is being collected in the MICS6. It provides an important update on the estimated prevalence of severe functional difficulty associated with learning in middle- and low-income countries (age 3-4 years 2.0\% (95\% Cl 1.6\%-2.4\%); age 5-17 years $1.9 \%(95 \% \mathrm{Cl} 1.7 \%-2.1 \%) .{ }^{19}$ Overall, the ascertained prevalence of severe functional difficulty associated with learning is similar to the estimated prevalence of intellectual disability among children in high income countries $(1.8 \%, 95 \% \mathrm{Cl}$ 1.5\%-2.1\%). ${ }^{2}$ However, given that there exist good grounds for believing that the prevalence of severe functional difficulty associated with learning (and intellectual disability) should increase as country wealth decreases, ${ }^{3,4,10,16}$ these data suggest that the measure of severe functional difficulty associated with learning may underestimate the prevalence of intellectual disability.

Of much greater concern, however, is the evidence that (when compared to alternative measures of child development collected in MICS6) the risks of making potential false positive and false negative errors are associated with two important indicators of family socio-economic position (SEP) namely 
relative household wealth and level of maternal education. Families with lower SEP are more likely to make potential false negative errors (not identifying their child as having difficulty learning when other data suggest that this may be the case). In contrast, families with higher SEP are more likely to make potential positive negative errors (identifying their child as having difficulty learning when other data suggest that this may not be the case). Similar socio-economic gradients in such errors have previously been reported in high-income countries. ${ }^{21}$ In addition, the WGDS concluded that 'research shows that in responding to questions about disability in the household, children and people of lower socioeconomic status are often overlooked, making them even more underidentified. ${ }^{22}$ The combined effect of these potential errors is that occurrence of severe functional difficulty associated with learning is likely to be overestimated among families with higher SEP and underestimated among families with lower SEP. This is particularly problematic for programs committed to high standards of equity by ensuring that their data can be effectively disaggregated by SEP/poverty and that no children will be 'left behind'. ${ }^{30-32}$

\section{Limitations of this study}

The main limitation of the study is that the alternative measures of child development used in the study have an unknown relationship with intellectual disability. For example, concerns have been expressed about the sensitivity of current ECDI items for detecting developmental delay. ${ }^{14,33}$ In addition, low numeracy will clearly include a significant proportion of children without intellectual disability. The use of alternative measures that are over inclusive will inflate estimates of potential false negative errors and deflate estimates of potential false positive errors. Given that the results indicated social gradients in both types of error, this limitation is unlikely have an impact on the general conclusions drawn.

\section{Conclusions}

The use of the MICS6 measure of severe functional difficulty associated with learning as a proxy indicator for intellectual disability needs to be used with caution given: (1) it would probably underestimate the overall prevalence of intellectual disability in middle and low income countries; and (2) it is likely to be overestimate prevalence among families with higher SEP and underestimate prevalence among families with lower SEP. For children under five, it may be preferable at this point in time to use ECDI items to identify young children at risk of 'significant cognitive delay' as a proxy indicator for intellectual disability, ${ }^{16}$ or a combination of ECDI and WGDS items. Given that performance on the these ECDI items is related to age, consideration should be given to possibly restricting its use to four-year-old children. It should be noted, given concerns about the sensitivity of current ECDI items for detecting developmental delay, a revised and extended 20-item version of the ECDI (ECDI2030) has been developed. The ECDI 2030 contains 10-items in the 'learning' domain and its incorporation in future rounds of MICS surveys is likely to provide a much more robust basis for identifying young children at risk of intellectual disability.

\section{References}

1. Emerson E, Fujiura GT, Hatton C. International perspectives. In: Odom SL, Horner RH, Snell M, Blacher J, eds. Handbook on Developmental Disabilities. New York: Guilford Press; 2007.

2. Maulik PK, Mascarenhas MN, Mathers CD, Dua T, Saxena S. Prevalence of intellectual disability: A meta-analysis of population-based studies Research in Developmental Disabilities. 2011;32:419-436.

3. Black MM, Walker SP, Fernald LCH, et al. Early childhood development coming of age: Science through the life course. Lancet. 2016;389:77-90.

4. Walker SP, Wachs TD, Gardner JM, et al. Child development: Risk factors for adverse outcomes in developing countries. Lancet. 2007;369:145-157. 
5. Walker SP, Wachs TD, Grantham-McGregor S, et al. Inequality in early childhood: risk and protective factors for early child development. Lancet. 2011;378:1325-1338.

6. Durkin MS, Schupf N, Stein ZA, Susser MW. Childhood Cognitive Disability. In: Wallace RB, ed. Public Health and Preventive Medicine,15th ed. Stamford, CT: Appleton \& Lange; 2007:1173-1184.

7. UNICEF. Monitoring the Situation of Children and Women for 20 Years: The Multiple Indicator Cluster Surveys (MICS) 1995-2015. New York: UNICEF; 2015.

8. Khan S, Hancioglu A. Multiple Indicator Cluster Surveys: Delivering Robust Data on Children andWomen across the Globe. Studies in Family Planning. 2019;50:279-286.

9. Shonkoff JP, Garner AS. The lifelong effects of early childhood adversity and toxic stress. Pediatrics. 2012;129:e232-246.

10. Grantham-McGregor S, Cheung YB, Cueto S, et al. Developmental potential in the first 5 years for children in developing countries. Lancet. 2007;369:60-70.

11. Engle PL, Black MM, Behrman JR, et al. Strategies to avoid the loss of developmental potential in more than 200 million children in the developing world. Lancet. 2007;369:229242.

12. Engle PL, Fernald LCH, Alderman $\mathrm{H}$, et al. Strategies for reducing inequalities and improving developmental outcomes for young children in low-income and middle-income countries. Lancet. 2011;378 1339-1353.

13. Grantham-McGregor SM, Fernald LCH, Kagawa RM, Walker S. Effects of integrated child development and nutrition interventions on child development and nutritional status. Annals of the New York Acadamy of Sciences. 2014;1308:11-32.

14. McCoy DC, Peet ED, Ezzati M, et al. Early Childhood Developmental Status in Low- and Middle-Income Countries: National, Regional, and Global Prevalence Estimates Using Predictive Modelling. PLoS Medicine. 2016;13 e1002034.

15. UNICEF. The formative years: UNICEF's work on measuring early childhood development. New York: UNICEF; 2014.

16. Emerson E, Savage A, Llewellyn G. Significant cognitive delay among 3- to 4-year old children in low- and middle-income countries: prevalence estimates and potential impact of preventative interventions. International Journal of Epidemiology. 2018;47:1465-1474.

17. Emerson E, Savage A. Acute respiratory infection, diarrhoea and fever in young children at risk of intellectual disability in 24 low-and middle-income countries. Public Health. 2017;142:85-93.

18. Emerson E, Savage A, Llewellyn G. Prevalence of underweight, wasting and stunting among young children with a significant cognitive delay in 47 low and middle-income countries. Journal of Intellectual Disability Research. 2020;64:93-102.

19. Cappa C, Mont D, Loeb M, et al. The Development and Testing of a Module on Child Functioning for Identifying Children with Disabilities on Surveys. III: Field Testing. Disability and Health Journal. 2018;11:510-518.

20. Robertson J, Emerson E, Hatton C, Yasamy MT. The identification of children with, or at significant risk of, intellectual disabilities in low- and middle-income countries: A Review. Journal of Applied Research in Intellectual Disabilities. 2012;25:99-118.

21. Emerson E, Felce D, Stancliffe R. Issues concerning self-report data and population-based data sets involving people with intellectual disabilities. Intellectual and Developmental Disabilities. 2013;51:333-348.

22. Loeb M, Mont D, Cappa C, De Palma E, Madans J, Crialesi R. The development and testing of a module on child functioning for identifying children with disabilities on surveys. I:

Background. Disability \& Health Journal. 2018;11:495-501.

23. Gochyyev P, Mizunoya S, Cardoso M. Validity and reliability of the MICS foundational learning module. MICS Methodological Papers, No. 9. New York: Data and Analytics Section, Division of Data, Research and Policy, UNICEF; 2019. 
24. World Health Organization. Closing the gap in a generation: Health equity through action on the social determinants of health. Final report of the Commission on the Social Determinants of Health. Geneva: World Health Organization; 2008.

25. World Bank. World Bank Country and Lending Groups. $<$ https://datahelpdesk.worldbank.org/knowledgebase/articles/906519-world-bank-countryand-lending-groups > accessed 08/19/2017. 2017.

26. World Bank. The World Bank Atlas method - detailed methodology. $<$ https://datahelpdesk.worldbank.org/knowledgebase/articles/378832-what-is-the-worldbank-atlas-method > accessed 08/19/2017. 2017.

27. World Bank. GNI per capita, Atlas method (current US\$). $<$ http://data.worldbank.org/indicator/NY.GNP.PCAP.CD?view=chart $>$ accessed 08/19/2017. 2017.

28. Rutstein SO. The DHS Wealth Index: Approaches for Rural and Urban Areas. DHS Working Papers No. 60. Calverton, Maryland: Macro International Inc; 2008.

29. Rutstein SO, Johnson K. The DHS Wealth Index: DHS Comparative Reports No. 6. Calverton, Maryland: ORC Macro 2004.

30. UNICEF. For every child, a fair chance: The promise of equity. New York: UNICEF; 2015.

31. UNICEF. The State of the World's Children 2016: A Fair Chance for Every Child New York: UNICEF; 2016.

32. United Nations Economic and Social Council Statistical Commission. Report of the Interagency and Expert Group on Sustainable Development Goal Indicators. New York: United Nations Economic and Social Council; 2016.

33. Lu C, Cuartas J, Fink G, et al. Inequalities in early childhood care and development in low/middle-income countries: 2010-2018. BMJ Global Health. 2020;5:e002314. 


\begin{tabular}{|c|c|c|c|c|c|}
\hline & \multirow{2}{*}{$\begin{array}{l}\text { pcGNI } \\
(2018)\end{array}$} & \multicolumn{2}{|c|}{ Age 2-4 } & \multicolumn{2}{|c|}{ Age 5-17 } \\
\hline & & $\begin{array}{r}\text { Sample } \\
\text { Size }\end{array}$ & Prevalence & $\begin{array}{r}\text { Sample } \\
\text { Size }\end{array}$ & Prevalence \\
\hline \multicolumn{6}{|l|}{ Upper Middle-Income } \\
\hline Montenegro & $\$ 8,430$ & 698 & $0.2 \%(0.0-1.5)$ & 1,156 & $1.3 \%(0.8-2.1)$ \\
\hline Suriname & $\$ 5,210$ & 2,716 & $0.9 \%(0.6-1.3)$ & 3,966 & $2.2 \%(1.8-2.7)$ \\
\hline Iraq & $\$ 5,040$ & 10,175 & $0.7 \%(0.5-0.9)$ & 15,592 & $1.2 \%(1.0-1.4)$ \\
\hline Georgia & $\$ 4,440$ & 1,605 & $0.9 \%(0.5-1.6)$ & 3,739 & $1.4 \%(1.1-1.8)$ \\
\hline Pooled estimate & & 15,194 & $0.7 \%(0.5-0.9)$ & 24,453 & $1.3 \%(1.0-1.5)$ \\
\hline \multicolumn{6}{|l|}{ Lower Middle-Income } \\
\hline Mongolia & $\$ 3,660$ & 3,803 & $0.4 \%(0.2-0.7)$ & 7,443 & $0.7 \%(0.5-0.9)$ \\
\hline Tunisia & $\$ 3,500$ & 2,173 & $0.8 \%(0.5-1.3)$ & 4,931 & $1.2 \%(0.9-1.5)$ \\
\hline Kiribati & $\$ 3,140$ & 1,267 & $2.0 \%(1.4-2.9)$ & 2,261 & $2.7 \%(2.1-3.5)$ \\
\hline Lao PDR & $\$ 2,450$ & 7,205 & $0.9 \%(0.7-1.1)$ & \multicolumn{2}{|c|}{ Data not collected } \\
\hline Ghana & $\$ 2,130$ & 5,406 & $3.9 \%(3.4-4.4)$ & 8,941 & $5.3 \%(4.9-5.8)$ \\
\hline Zimbabwe & $\$ 1,790$ & 3,766 & $0.5 \%(0.3-0.8)$ & 7,033 & $2.4 \%(2.1-2.8)$ \\
\hline Bangladesh & $\$ 1,750$ & 14,055 & $1.2 \%(1.0-1.4)$ & 39,504 & $1.6 \%(1.5-1.7)$ \\
\hline Lesotho & $\$ 1,390$ & 2,049 & $0.8 \%(0.5-1.3)$ & 4,998 & $0.9 \%(0.7-1.2)$ \\
\hline Kyrgyz Republic & $\$ 1,220$ & 2,167 & $0.3 \%(0.1-0.6)$ & 3,890 & $0.4 \%(0.2-0.7)$ \\
\hline Pooled estimate & & 41,891 & $1.5 \%(1.4-1.6)$ & 79,001 & $2.1 \%(1.9-2.3)$ \\
\hline \multicolumn{6}{|l|}{ Low Income } \\
\hline The Gambia & $\$ 710$ & 6,172 & $1.5 \%(1.2-1.8)$ & 5,711 & $1.5 \%(1.2-1.8)$ \\
\hline Togo & $\$ 660$ & 2,983 & $2.0 \%(1.6-2.6)$ & 4,969 & $2.0 \%(1.6-2.4)$ \\
\hline Madagascar & $\$ 510$ & 7,625 & $4.4 \%(4.0-4.9)$ & 11,978 & $2.9 \%(2.6-3.2)$ \\
\hline DR Congo & $\$ 490$ & 12,756 & $2.9 \%(2.6-3.2)$ & 14,027 & $1.3 \%(1.1-1.5)$ \\
\hline Sierra Leone & $\$ 490$ & 7,105 & $3.2 \%(2.8-3.6)$ & 11,030 & $1.9 \%(1.7-2.2)$ \\
\hline Pooled Estimate & & 36,637 & $3.1 \%(2.5-4.0)$ & 47,715 & $1.7 \%(1.4-2.1)$ \\
\hline \multicolumn{6}{|l|}{ All Countries } \\
\hline Pooled Estimate & & 93,722 & $2.1 \%(2.0-2.2)$ & 151,193 & $1.9 \%(1.7-2.1)$ \\
\hline
\end{tabular}




\begin{tabular}{|c|c|c|c|c|c|c|}
\hline \multirow[t]{2}{*}{ Country Classification } & \multicolumn{3}{|c|}{ Age 2-4 } & \multicolumn{3}{|c|}{ Age 5-17 } \\
\hline & $\begin{array}{r}\text { Sample } \\
\text { size }\end{array}$ & FDAL & $S C D$ & $\begin{array}{r}\text { Sample } \\
\text { size }\end{array}$ & FDAL & $\begin{array}{r}\text { Low } \\
\text { Numeracy } \\
\end{array}$ \\
\hline Middle Income & 31,320 & $-0.036 * * *$ & $-0.109 * * *$ & 44,127 & $-0.047 * * *$ & $-0.194 * * *$ \\
\hline Low Income & 38,039 & $-0.072 * * *$ & $-0.162 * * *$ & 31,382 & $-0.022 * * *$ & $-0.281 * * *$ \\
\hline All countries & 69,359 & $-0.049 * * *$ & $-0.105^{* * *}$ & 75,959 & $-0.038 * * *$ & $-0.215^{* * *}$ \\
\hline
\end{tabular}




\begin{tabular}{|c|c|c|c|c|}
\hline \multirow{2}{*}{$\begin{array}{l}\text { Country Classification } \\
\text { Group }\end{array}$} & \multicolumn{2}{|c|}{ Age 2-4 } & \multicolumn{2}{|c|}{ Age 5-17 } \\
\hline & $F D A L$ & $S C D$ & $F D A L$ & Low Numeracy \\
\hline Middle Income & $\begin{array}{l}1.06 \\
(0.87-1.29)\end{array}$ & $\begin{array}{l}1.04 \\
(0.96-1.13)\end{array}$ & $\begin{array}{l}1.13^{*} \\
(1.00-1.28)\end{array}$ & $\begin{array}{l}1.18^{* * *} \\
(1.12-1.24)\end{array}$ \\
\hline Low Income & $\begin{array}{l}1.16^{*} \\
(1.03-1.31)\end{array}$ & $\begin{array}{l}1.03 \\
(1.00-1.06)\end{array}$ & $\begin{array}{l}1.23^{*} \\
(1.04-1.45) \\
\end{array}$ & $\begin{array}{l}0.92^{* * *} \\
(0.88-0.97) \\
\end{array}$ \\
\hline All countries & $\begin{array}{l}1.12^{*} \\
(1.01-1.24)\end{array}$ & $\begin{array}{l}1.02 \\
(0.99-1.05)\end{array}$ & $\begin{array}{l}1.16^{* *} \\
(1.05-1.28)\end{array}$ & $\begin{array}{l}1.04^{*} \\
(1.01-1.08)\end{array}$ \\
\hline
\end{tabular}




\begin{tabular}{|c|c|c|c|c|}
\hline & \multicolumn{2}{|c|}{ Potential False Negative Error } & \multicolumn{2}{|c|}{ Potential False Positive Error } \\
\hline & Age 3-4 & Age 7-14 & Age 3-4 & Age $7-14$ \\
\hline \multicolumn{5}{|l|}{ Middle-Income Countries } \\
\hline \multicolumn{5}{|l|}{ Wealth quintile } \\
\hline 1 (poorest) & $2.74 * * *(2.29-3.28)$ & $4.58 * * *(3.94-5.33)$ & $0.95(0.68-1.34)$ & $1.29(1.00-1.67)$ \\
\hline 2 & $2.34 * * *(1.96-2.79)$ & $2.94 * * *(2.52-3.43)$ & $1.06(0.76-1.49)$ & $1.43 * *(1.12-1.83)$ \\
\hline 3 & $2.05^{* * *}(1.71-2.45)$ & $2.82 * * *(2.42-3.29)$ & $1.04(0.73-1.47)$ & $1.44^{* *}(1.13-1.83)$ \\
\hline 4 & $1.48 * * *(1.22-1.78)$ & $2.10 * * *(1.79-2.46)$ & $0.83(0.56-1.24)$ & $1.55^{* *}(1.23-1.95)$ \\
\hline 5 & 1 (ref) & 1 (ref) & 1 (ref) & 1 (ref) \\
\hline \multicolumn{5}{|l|}{ Highest Educational } \\
\hline None/pre-primary & $1.88 * * *(1.69-2.09)$ & $2.65 * * *(2.46-2.84)$ & $0.70 * *(0.54-0.90)$ & $0.75 * * *(0.67-0.85)$ \\
\hline Primary & $1.39 * * *(1.26-1.53)$ & $1.59 * * *(1.47-1.71)$ & $0.76 * *(0.62-0.93)$ & $0.80 * * *(0.72-0.90)$ \\
\hline Secondary or higher & 1 (ref) & 1 (ref) & 1 (ref) & 1 (ref) \\
\hline \multicolumn{5}{|l|}{ Rural/Urban } \\
\hline Rural & $1.07(0.97-1.18)$ & $1.11 *(1.02-1.20)$ & $1.71^{* * *}(1.28-2.30)$ & $0.83 * * *(0.75-0.92)$ \\
\hline Urban & 1 (ref) & 1 (ref) & 1 (ref) & 1 (ref) \\
\hline \multicolumn{5}{|l|}{ Low Income Countries } \\
\hline \multicolumn{5}{|l|}{ Wealth quintile } \\
\hline 1 (poorest) & $2.64 * * *(2.44-2.85)$ & $9.75 * * *(8.05-11.81)$ & $0.86(0.47-1.59)$ & $0.63 * * *(0.50-0.80)$ \\
\hline 2 & $2.40 * * *(2.22-2.59)$ & $8.09 * * *(6.67-9.80)$ & $1.35(0.75-2.43)$ & $0.70 * *(0.55-0.89)$ \\
\hline 3 & $1.97 * * *(1.82-2.13)$ & $5.55^{* * *}(4.57-6.73)$ & $1.12(0.61-2.06)$ & $0.92(0.77-1.10)$ \\
\hline 4 & $1.36 * * *(1.26-1.47)$ & $3.94 * * *(3.26-4.77)$ & $1.90 *(1.13-3.19)$ & $0.89(0.77-1.03)$ \\
\hline 5 & 1 (ref) & 1 (ref) & 1 (ref) & 1 (ref) \\
\hline \multicolumn{5}{|l|}{ Highest Educational } \\
\hline None/pre-primary & $1.01(0.97-1.05)$ & $1.86 * * *(1.74-2.00)$ & $1.04(0.75-1.45)$ & $0.44 * * *(0.36-0.55)$ \\
\hline Primary & $0.95 * *(0.91-0.98)$ & $1.23 * * *(1.15-1.32)$ & $1.28(0.99-1.66)$ & $0.72 * * *(0.64-0.81)$ \\
\hline Secondary or higher & 1 (ref) & 1 (ref) & 1 (ref) & 1 (ref) \\
\hline Rural/Urban & & & & \\
\hline
\end{tabular}




\begin{tabular}{|c|c|c|c|c|}
\hline Rural & $0.90 * * *(0.86-0.95)$ & $1.15^{* * *}(1.07-1.23)$ & $\begin{array}{l}1.45^{*} \\
(1.05-2.02) \\
\end{array}$ & $1.22 *(1.01-1.47)$ \\
\hline Urban & 1 (ref) & 1 (ref) & 1 (ref) & 1 (ref) \\
\hline \multicolumn{5}{|l|}{ All Countries } \\
\hline \multicolumn{5}{|l|}{ Wealth quintile } \\
\hline 1 (poorest) & $2.30 * * *(2.15-2.46)$ & $6.34 * * *(5.63-7.13)$ & $0.92(0.66-1.29)$ & $0.88(0.76-1.02)$ \\
\hline 2 & $2.11 * * *(1.97-2.26)$ & $4.79 * * *(4.25-5.39)$ & $1.29(0.93-1.78)$ & $0.99(0.86-1.13)$ \\
\hline 3 & $1.81 * * *(1.69-1.93)$ & $3.85 * * *(3.41-4.33)$ & $1.11(0.79-1.56)$ & $1.06(0.94-1.20)$ \\
\hline 4 & $1.36 * * *(1.27-1.46)$ & $2.79 * * *(2.47-3.14)$ & $1.40 *(1.02-1.91)$ & $1.07(0.96-1.20)$ \\
\hline 5 & 1 (ref) & 1 (ref) & 1 (ref) & 1 (ref) \\
\hline \multicolumn{5}{|l|}{ Highest Educational } \\
\hline None/pre-primary & $1.42 * * *(1.36-1.48)$ & $2.36 * * *(2.25-2.48)$ & $0.72 * *(0.59-0.88)$ & $0.66 * * *(0.60-0.74)$ \\
\hline Primary & $1.23^{* * *}(1.18-1.28)$ & $1.54 * * *(1.46-1.62)$ & $0.82 * *(0.70-0.95)$ & $0.81^{* * *}(0.75-0.88)$ \\
\hline Secondary or higher & 1 (ref) & 1 (ref) & 1 (ref) & 1 (ref) \\
\hline \multicolumn{5}{|l|}{ Rural/Urban } \\
\hline Rural & $0.99(0.95-1.03)$ & $1.08 * *(1.03-1.14)$ & $1.57 * * *(1.27-1.94)$ & $0.91 *(0.83-0.99)$ \\
\hline Urban & 1 (ref) & 1 (ref) & 1 (ref) & 1 (ref) \\
\hline
\end{tabular}

